\title{
STRATEGI NAFKAH MASYARAKAT ADAT KASEPUHAN SINAR RESMI DI TAMAN NASIONAL GUNUNG HALIMUN SALAK
}

\author{
Livelihoods Strategies in Kasepuhan Sinar Resmi of Gunung Halimun Salak National Park \\ Zuhaida Khoirun Niswah*) dan Soeryo Adiwibowo \\ Departemen Sains Komunikasi dan Pengembangan Masyarakat, Fakultas Ekologi Manusia, IPB
}

\begin{abstract}
This research essentially aims to see the change of livelihood strategies in Kasepuhan Sinar Resmi which resulted of changes in access of natural resources. The methods of this research through a qualitative approach with quantitative data supported. Qualitative approach, obtained by conducting in-depth interviews with informants then used to see the extent access of natural resources on Kasepuhan Sinar Resmi people before and after the expansion of Gunung Halimun Salak National Park, as well as a collaborative effort that was built by the Gunung Halimun Salak National Park which can become an alternative source of livelihood opportunities for households of Kasepuhan Sinar Resmi people. Quantitative data was collected using survey method with purposive sampling technique by taking 30 households as respondents. The conclusion of this research, there is no change in livelihood strategies due to changes in access of natural resources on indigenous people of Kasepuhan Sinar Resmi due to the expansion of Gunung Halimun Salak National Park.
\end{abstract}

Keywords: Acces of natural resources, Kasepuhan Sinar Resmi, Livelihood strategies

\begin{abstract}
ABSTRAK
Penelitian ini pada dasarnya bertujuan untuk melihat perubahan strategi nafkah pada masyarakat adat Kasepuhan Sinar Resmi sebagai akibat dari perubahan akses terhadap sumberdaya alam. Metode penelitian ini adalah pendekatan kualitatif dan data kuantitatif pendukung. Pendekatan kualitatif, diperoleh melalui wawancara mendalam dengan narasumber yang digunakan untuk mengetahui perubahan akses sumberdaya alam masyarakat Kasepuhan Sinar Resmi sebelum dan sesudah perluasan Taman Nasional Gunung Halimun Salak, Sebagai upaya kolaboratif yang dibangun oleh pihak Taman Nasional Gunung Salak yang dapat menjadi peluang alternatif sumber nafkah bagi masyarakat adat Kasepuhan Sinar Resmi. Data kuantitatif dikumpulkan menggunakan metode survey dengan teknik purposive sampling dengan mengambil 30 rumahtangga sebagai responden. Kesimpulan dari penelitian ini, tidak terdapat perubahan pada strategi nafkah akibat berubahnya akses sumberdaya alam pada masyarakat adat Kasepuhan Sinar Resmi dikarenakan perluasan Taman Nasional Gunung Salak.
\end{abstract}

Kata Kunci : akses sumberdaya alam, kasepuhan Sinar Resmi, strategi nafkah

\section{PENDAHULUAN}

\section{Latar Belakang}

Penetapan kawasan konservasi merupakan salah satu upaya pemerintah unutk menanggulangi kerusakan sumberdaya alam yang sering terjadi saat ini. Adanya kebijakan pemerintah mengenai penetepan kawasan konservasi berpengaruh positif terhadap keberlangsungan sumberdaya alam. Akan tetapi, kebijakan tersebut dapat menimbulkan masalah ketika terbentur dengan keberadaan masyarakat adat yang sudah terlebih dahulu mendiami kawasan konservasi tersebut. Kebijakan pemerintah salah satunya melalui perluasan Taman Nasional Gunung Halimun Salak (TNGHS) yang didasarkan pada Surat Keputusan Menteri Kehutanan No. 175/Kpts-II/2003.

Kawasan TNGHS merupakan kawasan hutan pegunungan hujan tropis alam terbesar yang terdapat di Jawa BaratBanten yang mana, baik di dalam kawasan TNGHS dihuni sekitar 250.000 jiwa manusia, termasuk masyarakat adat (TNGHS, 2007). Salah satu masyarakat adat yang mendiami kawasan TNGHS adalah masyarakat adat Kasepuhan Sinar Resmi. Masyarakat adat Kasepuhan Sinar Resmi merupakan salah satu masyarakat adat yang sudah sejak lama mendiami kawasan TNGHS, yang mereka yakini sebagai tanah leluhur. Dalam memenuhi kebutuhan hidupnya, masyarakat kasepuhan bergantung pada sumberdaya alam yang berorientasi pada sistem pertanian tradisional yang umumnya memanfaatkan sumberdaya hutan dan lahan dalam berbagai cara, yaitu huma, sawah, dan kebun. Adanya perluasan TNGHS dapat mengurangi akses masyarakat kasepuhan terhadap sumberdaya alam.

Keterbatasan akses terhadap sumberdaya alam dapat mendorong masyarakat untuk melakukan bentuk strategi nafkah. Konsep strategi nafkah merupakan suatu landasan 
pilihan aktivitas nafkah yang dilakukan rumahtangga untuk memenuhi kebutuhan atau mencapai tujuan rumahtangga. Strategi nafkah ditentukan oleh kemampuan masyarakat dalam mengkombinasikan berbagai sumber nafkah yaitu modal alami, modal fisik, modal finansial, modal sumber daya manusia, dan modal sosial (Ellis, 2000). Kebijakan mengenai perluasan kawasan TNGHS dapat menjadi indikator kemungkinan adanya perubahan strategi nafkah dengan segala keterbatasan akses sumberdaya alam yang dialami oleh masyarakat kasepuhan.

\section{Perumusan Masalah}

Merujuk pada latar belakang yang telah dijelaskan sebelumnya, perbedaan aturan antara TNGHS dan masyarakat Kasepuhan Sinar Resmi menyebabkan terjadinya saling klaim atas sumberdaya alam. Sumberdaya alam merupakan sumber nafkah penting bagi masyarakat Kasepuhan Sinar Resmi yang menggantungkan hidupnya pada sektor pertanian. Adanya tumpang tindih klaim menyebabkan ketidakpastian nafkah yang dialami oleh masyarakat Kasepuhan Sinar Resmi. Perluasan kawasan TNGHS mengurangi akses masyarakat Kasepuhan Sinar Resmi terhadap sumberdaya alam khususnya lahan garapan yang bisa menyebabkan hilangnya sumber nafkah rumahtangga.

Melihat realita yang terjadi, lahan garapan sebagai sumberdaya alam yang aksesnya terbatas dapat menyebabkan adanya transformasi sumber-sumber nafkah. Melalui transformasi sumber-sumber nafkah inilah yang membuat masyarakat Kasepuhan Sinar Resmi melakukan bentuk-bentuk strategi nafkah untuk dapat bertahan hidup. Selain itu, kehidupan masyarakat kasepuhan yang mendiami kawasan taman nasional, tidak terlepas dari pengelolaan oleh pihak TNGHS. Pihak TNGHS juga memiliki peran dalam upaya pemberdayaan masyarakat kasepuhan melalui upaya kolaboratif. Upaya kolaboratif ini diharapkan mampu memberikan keuntungan bagi kedua belah pihak khususnya mengenai keberlanjutan kawasan konservasi dan kesejahteraan masyarakat kasepuhan. Berdasarkan pemaparan alasan di atas, pertanyaan yang akan dijawab dalam penelitian ini adalah :

1. Sejauh mana perluasan TNGHS mengubah akses sumberdaya alam masyarakat adat Kasepuhan Sinar Resmi?

2. Sejauh mana perubahan akses sumberdaya alam sesudah perluasan TNGHS membuat masyarakat adat Kasepuhan Sinar Resmi melakukan bentuk-bentuk strategi nafkah?

3. Apakah upaya kolaboratif yang dibangun oleh pihak TNGHS dapat dimanfaatkan sebagai peluang alternatif sumber nafkah bagi masyarakat adat Kasepuhan Sinar Resmi.

\section{Tujuan Penelitian}

1. Untuk mengetahui perubahan akses sumberdaya alam masyarakat adat Kasepuhan Sinar Resmi dikarenakan perluasan TNGHS.

2. Untuk mengetahui perubahan akses sumberdaya alam sesudah perluasan TNGHS membuat masyarakat adat Kasepuhan Sinar Resmi melakukan bentuk-bentuk strategi nafkah.

3. Untuk mengetahui adanya upaya kolaboratif yang dibangun oleh pihak TNGHS yang dapat dimanfaatkan sebagai peluang alternatif sumber nafkah bagi masyarakat adat Kasepuhan Sinar Resmi.

\section{PENDEKATAN TEORITIS}

\section{Definisi Masyarakat Adat}

Menurut Sangaji dalam Ningrat (2004) masyarakat adat merupakan kelompok masyarakat yang memiliki asalusul leluhur secara turun-temurun di wilayah geografis tertentu serta memiliki sistem nilai, ideologi, ekonomi, politik, budaya, sosial dan wilayah sendiri. Masyarakat adat kasepuhan juga termasuk masyarakat tradisional, seperti yang dikemukakan oleh Suhandi dalam Ningrat (2004) yang mencirikan masyarakat tradisional, antara lain: 1) Hubungan atau ikatan masyarakat desa dengan tanah sangat erat, 2) Sikap hidup dan tingkah laku yang magis religious, 3) Adanya kehidupan gotong-royong, 4) Memegang tradisi dengan kuat, 5) Menghormati para sesepuh, 6) Kepercayaan pada pimpinan lokal dan tradisional, 7) Organisasi kemasyarakatan yang relatif statis, dan 8) Tingginya nilai sosial.

\section{Pengertian Akses}

Pengertian akses dalam penelitian ini merujuk pada teori akses dari Peluso (2003) yang mendefinisikan akses sebagai kemampuan untuk memperoleh manfaat dari sesuatu. Dalam akses yang lebih diutamakan adalah kemampuan, dibandingkan kepemilikan yang ada di teori property. Akses dalam pengertiannya lebih pada bundle of power, yang mengandung arti bahwa memberikan perhatian pada wilayah yang lebih luas pada hubungan sosial yang mendesak dan memungkinkan orang untuk mendapatkan keuntungan dari sumberdaya tanpa menfokuskan diri pada hubungan kepemilikan semata. Akses lebih melihat pada masalah-masalah mengenai siapa yang memanfaatkan (dan siapa yang tidak memanfaatkan) sesuatu, dengan menggunakan cara apa, dan kapan (dalam keadaan seperti apa). Konsep kepemilikan ini meliputi berbagai jenis kumpulan hak, yang dapat berasal dari negara, adat, hukum agama, atau kerangka kerja normatif lainnya. Macpherson (1978) dalam Peluso (2003) menyatakan bahwa karakteristik kepemilikan sebagai suatu hak yang berarti suatu klaim dilaksanakan untuk menggunakan beberapa atau manfaat dari sesuatu.

\section{Konsep Strategi Nafkah}

Strategi nafkah menurut Dharmawan (2001) adalah segala kegiatan atau keputusan yang diambil anggota rumahtangga untuk bertahan hidup (survival) dan atau membuat hidup lebih baik. Tujuan dari bertahan hidup ini adalah membangun beberapa strategi untuk keamanan dan keseimbangan mata pencaharian rumahtangga. Dalam melakukan strategi bertahan (survival) untuk memenuhi kebutuhan hidupnya, rumahtangga memerlukan semacam modal atau bisa dikatakan sumber nafkah. Terdapat lima bentuk modal atau biasa disebut livelihood asset. Menurut Ellis (2000), kelima bentuk modal tersebut adalah modal sumberdaya ala, modal fisik, modal manusia, modal finansial, modal sosial.

Scoones dalam Ependi (2004) membagi strategi nafkah petani ke dalam tiga golongan besar, yaitu : 
1. Rekayasa sumber nafkah pertanian, merupakan usaha pemanfaatan sektor pertanian agar lebih efektif dan efisien baik melalui penambahan input eksternal berupa tenaga kerja atau teknologi (intensifikasi) maupun memperluas lahan garapan pertanian (ekstensifikasi).

2. Pola nafkah ganda, merupakan usaha yang dilakukan dengan cara mencari pekerjaan lain selain sektor pertanian untuk menambah pendapatan (diversifikasi pekerjaan).

3. Rekayasa spasial, merupakan usaha yang dilakukan dengan cara mobilisasi atau perpindahan penduduk baik secara permanen maupun sirkuler (migrasi).

Menurut Sconnes dalam Masithoh (2005), dalam melakukan strategi nafkah, rumahtangga petani bisa menerapkan salah satu kegiatan atau melakukan kombinasi dari ketiga bentuk strategi nafkah untuk memperoleh strategi yang paling efektif agar bisa bertahan hidup baik saat krisis maupun saat kondisi normal.

\section{Pengelolaan Kolaboratif}

Isu-isu mengenai konflik sumberdaya alam semakin hari semakin berkembang. Konflik ini tidak terlepas dari pihak-pihak yang berkepentingan seperti pemerintah, swasta, dan masyarakat lokal terkait dengan pengelolaan sumberdaya alam. Dalam meminimalisir konflik diperlukan solusi yaitu melalui kolaboratif.

Menurut IUCN (1996) dalam Indra dan Sabarudi (2009) pengelolaan kolaboratif adalah kemitraan antara lembaga pemerintah, komunitas lokal dan pengguna sumberdaya, lembaga non pemerintah, dan kelompok kepentingan lainnya dalam bernegosiasi dan menentukan kerangka kerja yang tepat tentang kewenangan dan tanggung jawab untuk mengelola daerah spesifik atau sumberdaya alam.

\section{Kerangka Pemikiran}

Perluasan Taman Nasional Gunung Halimun Salak (TNGHS) berdasarkan SK Menhut No.175/Kpts-II/2003 mengubah status dan rezim penguasaan atas sumberdaya alam yang menyebabkan akses masyarakat kasepuhan terbatas. Adanya perubahan akses ini, akankah membuat masyarakat kasepuhan melakukan bentuk-bentuk strategi nafkah.

Melalui strategi nafkah ini, rumahtangga memiliki alternatif atau pilihan-pilihan dalam kegiatan ekonomi mereka dengan memanfaatkan sumber nafkah yang mereka miliki agar mampu mencapai kesejahteraan hidup. Seiring dengan kehidupan masyarakat kasepuhan yang masih bergantung pada ketersediaan sumberdaya alam di kawasan TNGHS, sampai saat ini masih ada benturanbenturan diantara pihak kasepuhan dengan pihak TNGHS dikarenakan saling klaim terhadap sumberdaya alam. Upaya kolaboratif diharapkan mampu meminimalisir adanya benturan diantara kedua belah pihak, yang berorientasi pada keberlanjutan kawasan konservasi dan kesejahteraan masyarakat kasepuhan.

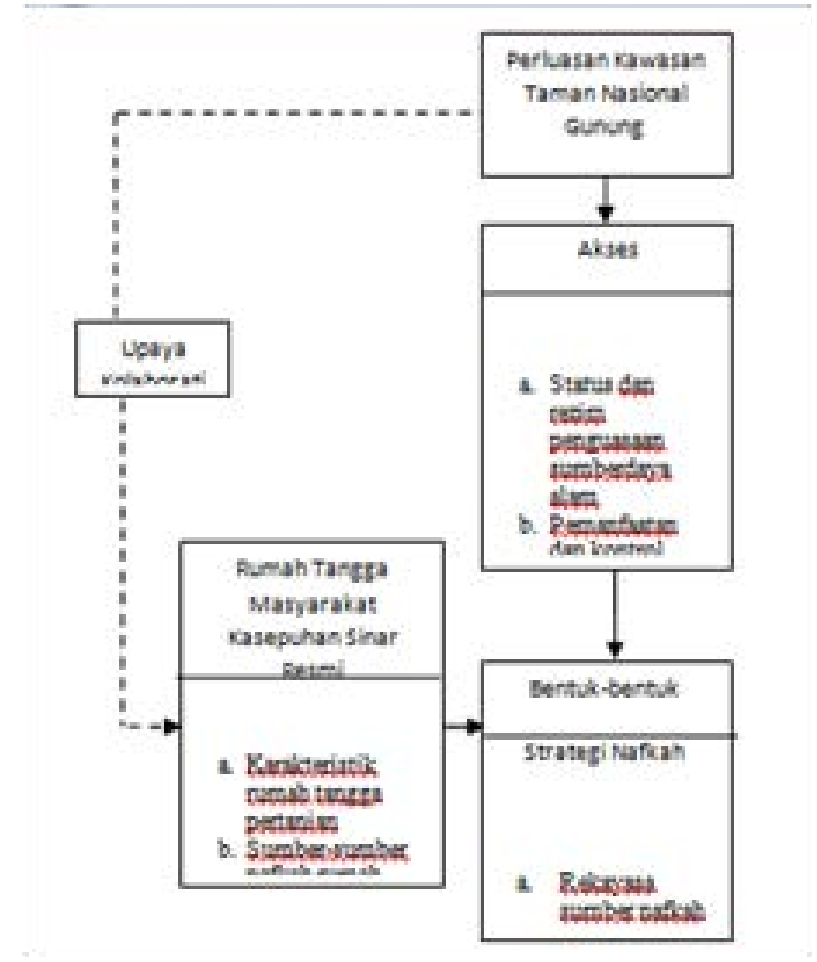

Keterangan $: \rightarrow:$ mempengaruhi

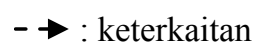

Gambar 1. Kerangka Pemikiran Strategi Nafkah Masyarakat Adat Kasepuhan Sinar Resmi di Taman Nasional Gunung Halimun Salak

\section{Hipotesis}

Terdapat perubahan strategi nafkah akibat berubahnya akses sumberdaya alam pada masyarakat adat Kasepuhan Sinar Resmi karena perluasan Taman Nasional Gunung Halimun Salak.

\section{PENDEKATAN LAPANGAN}

\section{Lokasi dan Waktu Penelitian}

Penelitian ini dilakukan di Kasepuhan Sinar Resmi, Kampung Cimapag, Desa Sirna Resmi, Kecamatan Cisolok, Kabupaten Sukabumi yang merupakan salah satu masyarakat adat yang mendiami kawasan Taman Nasional Gunung Halimun Salak. Penelitian dilakukan pada bulan Oktober-Desember 2010. Penelitian dilakukan di Kampung Cimapag yang merupakan salah satu kampung di Desa Sirna Resmi yang sebagian besar masyarakatnya merupakan incu putu (pengikut) Kasepuhan Sinar Resmi. Kampung Cimapag berjarak sekitar 2 km dari Kampung Sinar Resmi yang mana Kampung Sinar Resmi merupakan kampung yang menjadi pusat berlangsungnya kegiatankegiatan kasepuhan dan tempat dimana Ketua Adat Kasepuhan Sinar Resmi tinggal. Mayoritas masyarakat Kampung Cimapag bekerja sebagai petani. Lahan garapan yang digarap oleh masyarakat Kampung Cimapag sebagian besar termasuk dalam kawasan TNGHS. 


\section{Pendekatan Penelitian}

Metode dalam penelitian ini menggunakan pendekatan kualitatif dengan didukung data kuantitatif. Pendekatan kualitatif merupakan pendekatan dominan yang dilakukan. Pendekatan kualitatif, diperoleh dengan melakukan wawancara mendalam dengan informan terkait yang selanjutnya digunakan untuk melihat sejauh mana akses masyarakat kasepuhan terhadap sumberdaya alam sebelum dan sesudah perluasan TNGHS dan pengaruhnya terhadap strategi nafkah, serta upaya kolaboratif yang dibangun oleh pihak TNGHS yang dapat dimanfaatkan sebagai peluang alternatif sumber nafkah bagi rumahtangga masyarakat Kasepuhan Sinar Resmi. Data kuantitatif dikumpulkan dengan menggunakan metode survei. Metode survei dilakukan untuk mengetahui bentuk-bentuk strategi nafkah rumahtangga masyarakat Kasepuhan Sinar Resmi di Kampung Cimapag sebelum dan sesudah perluasan TNGHS. Metode survei dilakukan dengan mengumpulkan data responden sebanyak 30 rumahtangga dengan teknik purposive sampling.

\section{Teknik Pengumpulan Data}

Data yang digunakan dalam penelitian ini meliputi data primer dan data sekunder. Data primer diambil dari kuesioner dan panduan pertanyaan dari responden serta wawancara mendalam dengan beberapa informan. Data sekunder diperoleh dengan melakukan kajian pustaka dan menganalisis terhadap berbagai literatur. Semua informasi yang diperoleh melalui wawancara mendalam maupun pengamatan atau observasi didokumentasikan kembali ke dalam bentuk catatan harian, agar tidak terjadi distorsi pesan. Data primer maupun sekunder kedua-duanya sangat mendukung satu sama lain untuk menyempurnakan hasil penelitian. Semua metode tersebut digunakan dengan tujuan agar data yang diperoleh benar-benar akurat. Sehingga memudahkan peneliti untuk menyusun dan menyelesaikan penelitian ini.

\section{Teknik Analisis Data}

Data yang diperoleh oleh peneliti baik primer maupun sekunder akan diolah dengan cara mereduksi bagianbagian terpenting, sehingga didapatkan kesimpulan yang mewakili permasalahan yang ada. Data kuantitatif yang telah diperoleh, diolah, dan disajikan dengan menggunakan tabel frekuensi yang memperlihatkan bentuk-bentuk strategi nafkah rumahtangga masyarakat adat Kasepuhan Sinar Resmi baik sebelum perluasan TNGHS maupun sesudah perluasan TNGHS. Data kuantitatif yang disajikan, dianalisis secara deskriptif untuk melihat gambaran bentuk-bentuk strategi nafkah rumahtangga masyarakat adat Kasepuhan Sinar Resmi.

\section{GAMBARAN UMUM LOKASI PENELITIAN}

\section{Profil Kasepuhan Sinar Resmi}

Kasepuhan Sinar Resmi merupakan salah satu masyarakat adat yang mendiami kawasan TNGHS. Kasepuhan Sinar Resmi secara administratif terletak di Desa Sirna Resmi, Kecamatan Cisolok, Kabupaten Sukabumi, Provinsi Jawa Barat. Masyarakat Kasepuhan Sinar Resmi yang menjadi subyek dalam penelitian ini dilakukan di Kampung Cimapag, yang mayoritas menggarap lahan di kawasan TNGHS. Masyarakat adat Kasepuhan Sinar Resmi tidak pernah terlepas dari filosofi-filosofi hidup dan berbagai aturan adat yang sudah menjadi satu jiwa pada diri masyarakat kasepuhan sendiri. Sehingga, antara masyarakat kasepuhan dengan aturan adat serta filosofi hidup yang ada sudah terbentuk ikatan yang kuat. Masyarakat kasepuhan sangat bergantung pada ketersediaan alam karena mereka menggantungkan hidupnya pada sektor pertanian dengan sistem huma sebagai sistem pertanian padi yang merupakan warisan leluhur. Dalam pengelolaan sumberdaya alam khususnya sistem pertanian, masyarakat Kasepuhan Sinar Resmi tidak terlepas dari pengetahuan lokal dan aturan adat yang ada di dalamnya. Adanya perluasan TNGHS berdasarkan SK Menteri Kehutanan No. 175/ Kpts-II/2003, menyebabkan lahan garapan masyarakat kasepuhan menjadi bagian dari zonasi TNGHS. hal ini yang menyebabkan timbulnya tumpang tindih peraturan mengenai status lahan garapan masyarakat yang sampai saat ini masih menjadi sumber nafkah utama masyarakat Kasepuhan Sinar Resmi.

\section{Profil Taman Nasional Gunung Halimun Salak}

Taman Nasional Gunung Halimun Salak (TNGHS) merupakan wilayah yang mempunyai karakteristik kawasan pegunungan yang masih memiliki hutan hujan tropis di Jawa. Pada awalnya TNGHS merupakan kawasan hutan lindung dengan luas 39.941 ha selama periode 1924 1934 masa pemerintahan Hindia-Belanda. Pemerintah Hindia-Belanda pada tahun 1935 mengeluarkan kebijakan mengenai perubahan kawasan tersebut untuk menjadi cagar alam dengan nama Cagar Alam Gunung Halimun yang dikelola oleh Djawatan Kehutanan Jawa Barat (Jabar). Pada tahun 1977 Gubernur Jabar menyetujui usulan bahwa seluruh hutan lindung di wilayah Jabar diserahkan PHPA (Pelestarian Hutan dan Perlindungan Alam). Usulan mengenai perluasan kawasan cagar alam melebihi 40.000 ha diusulkan oleh PHPA, namun sebagian besar hutan telah dibuka menjadi lahan pertanian dan pemukiman. Sebagian hutan produksi juga masih merupakan hutan primer. Tahun 1978 kawasan Cagar Alam Gunung Halimun dikelola oleh Perum Perhutani dan tahun 1979 PHPA juga mulai mengelola kawasan ini yang sudah diperluas menjadi 40.000 ha. Berdasarkan Surat Keputusan Menteri Kehutanan No. 282/Kpts-II/1992 tanggal 28 Februari 1992 kawasan Cagar Alam Halimun ditetapkan menjadi salah satu taman nasional di Indonesia dengan nama Taman Nasional Gunung Halimun (TNGH) di bawah pengelolaan Taman Nasional Gunung Gede Pangrango (TNGGP). Pada tanggal 23 Maret 1997 pengelolaan TNGH dipegang oleh Unit Pelaksana Teknis Balai TNGH, Dirjen PHKA, dan Departemen Kehutanan. Melalui Surat Keputusan Menteri Kehutanan No. 175/Kpts-II/2003 pada tanggal 10 Juni 2003, kawasan TNGH diperluas dengan luas total 113.357 ha dan bernama resmi Taman Nasional Gunung Halimun Salak (TNGHS).

\section{HASIL-HASIL PENELITIAN}

\section{Perubahan Akses Sumberdaya Alam}

Sebelum perluasan TNGHS, masyarakat Kasepuhan Sinar Resmi di Kampung Cimapag menggarap lahan di bawah pengelolaan Perum Perhutani. Dalam pengelolaan sumberdaya alam, Perum Perhutani melakukan kesepakatan dengan masyarakat kasepuhan mengenai pancang. Pancang inilah yang menjadi batas, antara mana lahan yang boleh digarap dan mana lahan yang tidak 
boleh digarap. Mekanisme aturan pancang adalah bahwa area yang berada di dalam pancang diperbolehkan bagi masyarakat untuk menanam, menggarap, memelihara, memanfaatkan, dan bermukim di area tersebut. Dalam menanam tanaman-tanaman kehutanan, masyarakat kasepuhan dilibatkan dan diijinkan menanam di lahan tersebut dengan sistem tumpang sari. Ketika masa panen, masyarakat dikenai pajak sekitar $10 \%$ untuk diserahkan kepada Perum Perhutani. Sebagai contoh, masyarakat mendapatkan keuntungan sekitar 100 ikat, maka 10 ikat diberikan untuk Perum Perhutani dan 90 ikat untuk masyarakat.

Berdasarkan SK Menteri Kehutanan No. 175/KptsII/2003 kawasan TNGHS mengalami perluasan. Perluasan TNGHS ini mengalihfungsikan kawasan yang dulunya dikelola oleh Perum Perhutani menjadi kawasan konservasi, termasuk di dalamnya lahan garapan masyarakat. Adanya perluasan ini mengakibatkan akses masyarakat atas lahan garapan dibatasi, karena aturan TNGHS menegaskan bahwa kawasan yang sudah menjadi kawasan konservasi tidak seharusnya dijadikan lahan garapan. Hal ini menyebabkan ada perbedaan akses ketika kawasan yang dulu dikelola oleh Perum Perhutani dengan kawasan yang sekarang dikelola secara penuh oleh TNGHS. Masyarakat kasepuhan sampai saat ini masih bisa menggarap lahan baik huma, sawah, dan kebun tetapi tidak boleh menebang kayu baik itu untuk kebutuhan seperti pembangunan rumah. Masyarakat kasepuhan sendiri hanya bisa menanam tanaman kebun kayu atau talun seperti jeunjing, manii, manglid, tisuk, jabon, dan lain-lain tetapi hasilnya tidak boleh ditebang. Aturan talun atau kebun kayu juga dirasa memberatkan masyarakat, karena talun dimanfaatkan masyarakat untuk dijual, membangun, ataupun memperbaiki rumah mereka yang notabene terbuat dari kayu dan bambu. Disini terlihat bahwa kontrol masyarakat atas lahan garapan menjadi terbatas, selain itu masyarakat sejauh ini masih memperoleh manfaat atas lahan garapan di dalam kawasan TNGHS tetapi tidak untuk dimiliki.

\section{Karakteristik Rumahtangga Pertanian Masyarakat Kasepuhan Sinar Resmi}

Rumahtangga masyarakat Kasepuhan Sinar Resmi pada dasarnya bergantung pada sumberdaya alam sebagai sumber nafkah, yakni melalui kegiatan pertanian. Kegiatan pertanian yang dilakukan oleh rumahtangga masyarakat kasepuhan dengan sistem pertanian tradisional khususnya tanaman padi. Penananam padi dilakukan di lahan kering (huma) kemudian dapat dilanjutkan dengan penanaman padi di sawah. Hal ini dikarenakan huma merupakan sistem pertanian warisan leluhur yang harus dikerjakan terlebih dahulu. Dalam melakukan kegiatan pertanian khususnya tanaman padi, baik di huma maupun di sawah terdapat berbagai prosesi yang disesuaikan dengan aturan adat yang berlaku. Mulai dari mempersiapkan lahan sampai dengan setelah masa panen, selalu diikuti dengan upacara ritual adat yang sudah sejak dahulu dilaksanakan oleh masyarakat kasepuhan. Tanaman padi sebagai komoditi utama, berdasarkan aturan adat yang berlaku di kasepuhan tidak diperbolehkan untuk dijual dan hanya digunakan untuk kebutuhan pangan rumahtangga. Tanaman padi juga hanya dipanen dalam satu tahun sekali. produktivitas tanaman padi pada rumahtangga masyarakat Kasepuhan Sinar Resmi di Kampung Cimapag yaitu 130 pocong/455 $\mathrm{kg} /$ musim panen. Selain menanam padi, masyarakat kasepuhan juga menanam komoditi tambahan untuk mendukung kegiatan pertanian. Melalui sistem tumpang sari, masyarakat menanam tanaman seperti palawija (jagung, singkong, dan ubi), buah-buahan (pisang dan alpukat), sayur-sayuran (kacang panjang, tomat, timun, dan buncis), kapulaga, dan kebun kayu (jeunjing, manglid, tisuk, jabon, jati putih, mahoni, bambu, manii, aren, pohon kopi, dan lainnya). Sistem pengairan dikelola secara bersama-sama antar rumahtangga dan memiliki kepengurusan sendiri yang disebut manintin. Sistem pengairan ini disebut solokan, yang berbentuk seperti parit dengan ukuran kurang lebih $1 \mathrm{~m}$ x $60 \mathrm{~cm}$. Lahan garapan yang dimanfaatkan oleh rumahtangga masyarakat Kasepuhan Sinar Resmi termasuk dalam kategori rendah $(<0.5$ hektar $)$ dengan rata-rata 6,5 patok $(2620,3 \mathrm{~m} 2)$. Lahan garapan ini masyarakat meliputi ada lahan SPPT (Surat Peringatan Pajak Terhutang) dan lahan kehutanan (taman nasional) yang secara hukum adat, lahan garapan ini merupakan lahan komunal masyarakat Kasepuhan Sinar Resmi.

\section{Bentuk-bentuk Strategi Nafkah Rumahtangga dan Akses Sumberdaya Alam}

Dalam hal pemenuhan kebutuhan, tidak dipungkiri bagi rumahtangga masyarakat Kasepuhan Sinar Resmi, sektor pertanian masih menjadi tumpuan hidup meskipun tidak menutup kemungkinan bagi mereka untuk memiliki mata pencaharian selain sektor pertanian. Melalui strategi nafkah yang dilakukan oleh rumahtangga, masyarakat kasepuhan dapat bertahan hidup dengan segala keterbatasan akses lahan garapan akibat perluasan TNGHS. Gambaran mengenai bentuk-bentuk strategi nafkah rumahtangga masyarakat Kasepuhan Sinar Resmi di Kampung Cimapag baik sebelum maupun sesudah perluasan TNGHS dapat dilihat pada Gambar 2. dan Gambar 3.

\section{Sebehum Perluasan TNGHS}

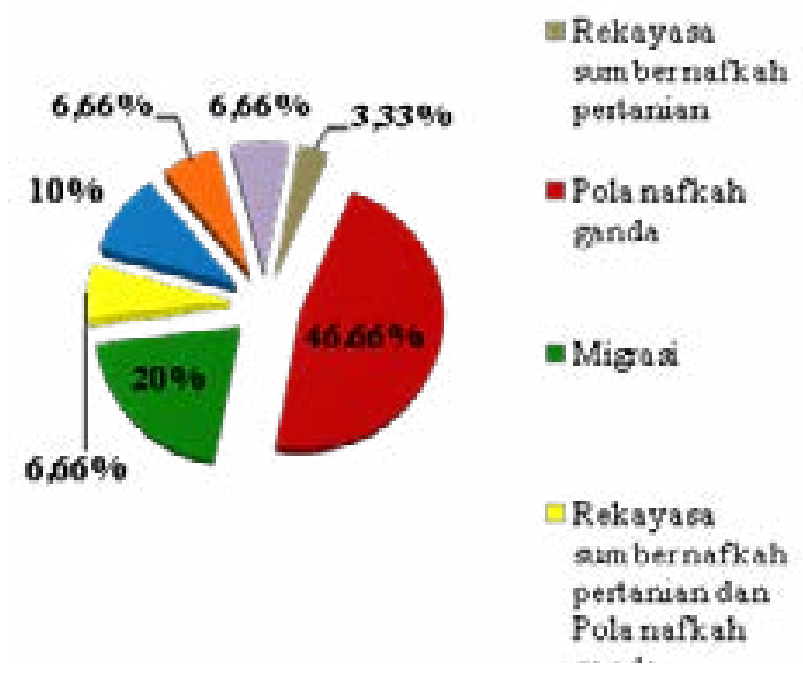

Sumber: Data Primer, 2010

Gambar 2. Persentase Bentuk-bentuk Strategi Nafkah Rumahtangga Masyarakat Adat Kasepuhan Sinar Resmi di Kampung Cimapag Sebelum Perluasan TNGHS 


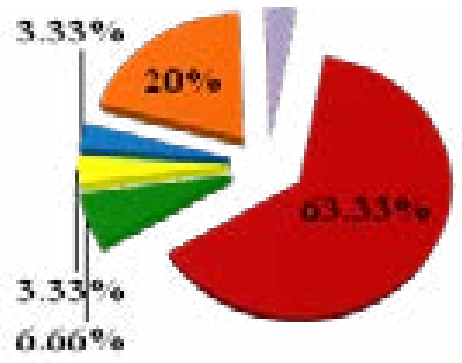

Rekayaea
sumbernafkeh
pertanian dan
Pola nafksh
ntedgaes
sumbernafkah
pertaraan dan
Migna
Polanafkah
ganda dan
Migas

Sumber: Data Primer, 2010

Gambar 3. Persentase Bentuk-bentuk Strategi Nafkah Rumahtangga Masyarakat Adat Kasepuhan Sinar Resmi di Kampung Cimapag Sesudah Perluasan TNGHS

Berdasarkan Gambar 2. dan Gambar 3. dapat dilihat bahwa baik sebelum maupun sesudah perluasan TNGHS, rumahtangga masyarakat Kasepuhan Sinar Resmi tidak menunjukkan perubahan strategi nafkah. Meskipun pada gambar menunjukkan bahwa masyarakat melakukan berbagai bentuk strategi nafkah yaitu rekayasa sumber nafkah pertanian, pola nafkah ganda dan migrasi Masyarakat memiliki nafkah selain sektor pertanian seperti buruh tani, penambang emas, buruh bangunan, memiliki warung, ojek, dan lain sebagainya. Akan tetapi nafkahnafkah tersebut hanya sebagai tambahan penghasilan yang dilakukan sesuai dengan kondisi dan peluang yang ada. Bentuk-bentuk strategi nafkah sudah dilakukan oleh rumahtangga dari sebelum perluasan TNGHS sampai sesudah perluasan TNGHS. Hal ini membuktikan bahwa adanya perubahan akses sumberdaya alam khususnya lahan garapan sesudah perluasan TNGHS tidak membuat masyarakat untuk beralih dari sektor pertanian. Logikanya, ketika akses sumberdaya alam sebagai sumber nafkah utama terbatas, maka terjadi ketidakpastian nafkah atau ada rasa ketidakamanan dalam mencari nafkah. Hal tersebut bisa menyebabkan rumahtangga beralih dari mata pencaharian sebelumnya dan mencari mata pencaharian lain.

Namun, hal ini justru berbeda dengan masyarakat kasepuhan yang mana dari sebelum adanya perluasan TNGHS sampai dengan sesudah adanya perluasan TNGHS masyarakat masih konsisten dengan kegiatan pertanian dan bentukbentuk strategi nafkah yang dilakukan tidak menunjukkan perubahan. Tidak adanya perubahan strategi nafkah dikarenakan masyarakat kasepuhan tetap memegang teguh tradisi leluhur yaitu sistem pertanian yang mereka jalani dari dahulu sampai sekarang. Pertanian bagi masyarakat kasepuhan sudah menjadi bagian dari budaya dan tradisi yang harus tetap dijaga dan dilestarikan. Sesuai dengan filosofi masyarakat kasepuhan yaitu "Ibu Bumi, Bapak Langit, Guru Mangsa" yang mana dalam kehidupannya, masyarakat harus menjaga keutuhan bumi beserta segala isinya sehingga keseimbangan alam pun tetap terjaga. Sistem pertanian ini tidak sekedar kegiatan pertanian yang secara umum menuju pada produktivitas, namun sistem pertanian di masyarakat kasepuhan sudah mengikat pada kehidupan masyarakat dan lebih berorientasi pada suatu interaksi yang kuat antar masyarakat dengan Tuhan, masyarakat dengan masyarakat serta masyarakat dengan alam dengan aturan adat yang sudah melekat di setiap sendi kehidupan masyarakat.

\section{KESIMPULAN DAN SARAN}

Berdasarkan data yang diperoleh di lapangan, menunjukkan bahwa tidak terdapat perubahan strategi nafkah akibat berubahnya akses sumberdaya alam pada masyarakat adat Kasepuhan Sinar Resmi dikarenakan perluasan TNGHS. Pernyataan tersebut menunjukkan bahwa hipotesis penelitian ditolak, dengan alasan : Pertama, terjadi perubahan akses masyarakat Kasepuhan Sinar Resmi terhadap sumberdaya alam dikarenakan perluasan TNGHS. Perubahan ini ditunjukkan dengan sudah tidak adanya kontrol masyarakat kasepuhan terhadap lahan garapannya yang ditetapkan sesuai dengan aturan TNGHS. Alasan kedua adalah perubahan akses sumberdaya alam pada masyarakat kasepuhan, tidak membuat masyarakat melakukan perubahan bentuk-bentuk strategi nafkah atau dengan kata lain beralih dari kegiatan pertanian. Masyarakat kasepuhan sudah melakukan bentuk strategi nafkah sebagai pendukung kegiatan nafkah baik dalam bentuk pola nafkah ganda maupun migrasi seperti menjadi buruh tani, menyadap aren, buruh bangunan, penambang emas, dan lain-lain baik sebelum perluasan maupun sesudah perluasan TNGHS.

Tidak adanya perubahan strategi nafkah dikarenakan sistem pertanian sudah menjadi bagian dari budaya tradisi leluhur yang sudah seharusnya dijaga dan dilestarikan. Sesuai dengan filosofi masyarakat kasepuhan yaitu "Ibu Bumi, Bapak Langit, Guru Mangsa" yang mana dalam kehidupannya, masyarakat harus menjaga keutuhan bumi beserta segala isinya sehingga keseimbangan alam pun tetap terjaga. Dalam kaitannya dengan upaya kolaboratif sebagai peluang alternatif sumber nafkah, masyarakat dapat memanfaatkan adanya program MKK (Model Kampung Konservasi). Salah satu kegiatan dalam program MKK adalah pembentukan kelompok MKK. Kelompok tersebut dapat mengajukan dana untuk modal usaha kegiatan ekonomi tambahan di bidang peternakan, perikanan, warung-warung kecil, dan lainnya. Melalui kegiatan MKK, masyarakat dapat memperoleh sumber nafkah tambahan selain sektor pertanian. Berdasarkan pada kesimpulan yang sudah dikemukakan, permasalahan kawasan TNGHS selalu bertumpu pada adanya tumpang tindih peraturan. Tidak bisa dipungkiri aturan adat yang dimiliki oleh masyarakat kasepuhan masih menjadi kekuatan bagi masyarakat untuk tetap bertahan dalam melakukan kegiatan pertanian, meskipun mereka menggarap di kawasan TNGHS. Oleh karena itu, hendaknya dalam pengelolaan sumberdaya alam yang melibatkan masyarakat kasepuhan di dalamnya perlu adanya pengakuan hukum adat yang sudah ada. Hal ini dilakukan demi keberlanjutan kawasan konservasi dan kesejahteraan masyararakat kasepuhan.

\section{DAFTAR PUSTAKA}

Dharmawan, Arya Hadi. 2001. Farm Household Livelihood Strategies and Socioeconomic Changes in Rural Indonesia. Kiel: Wissenschaftsverlag Vauk Kiel KG.

Ellis, Frank. 2000. Rural Livelihood and Diversity 
in Developing Countries. New York: Oxford University.

Ependi, Engken Parid. 2004. Analisis Sumberdaya Nafkah (Livehood Resource) dan Strategi Nafkah (Livehood Strategies) pada Dua Komunitas : Studi Kasus Komunitas Desa Banturujeg, Kecamatan Banturujeg, Kabupaten Majalengka dan Komunitas Desa Cisarua, Kecamatan Nanggung, Kabupaten Bogor, Provinsi Jawa Barat. Skripsi. Departemen Ilmu-Ilmu Sosial Ekonomi, Fakultas Pertanian, Institut Pertanian Bogor. Tidak Dipublikasikan.

Indra dan Subarudi.2009. Proses Pembelajaran dari Pembentukan Manajemen Kolaboratif di Taman Nasional Bunaken, Sulawesi Utara. http://www. coraltrianglecenter.org/downloads/NRM\%20 LessonsLearned ID.pdf. Diakses pada tanggal 20 September 2010.

Masithoh, Arifah Dewi. 2005. Analisis Strategi Nafkah Rumahtangga Petani Perkebunan Rakyat. (Studi Kajian Perbandingan : Komunitas Petani Perkebunan Teh Ciguha Jawa Barat dan Komunitas Petani Perkebunan Tebu Puri Jawa Timur. Skripsi. Departemen Ilmu-Ilmu Sosial dan Ekonomi, Fakultas Pertanian, Institut Pertanian Bogor. Tidak Dipublikasikan.

Ningrat, Andya Ayu. 2004. Karakteristik Lanskap Tradisional, di Halimun Selatan dan FaktorFaktor yang Mempengaruhinya: Sebuah Studi pda Kampung Kasepuhan di Kesatuan Adat Banten Kidul, Kampung Sinar Resmi, Desa Sirna Resmi, Kecamatan Cisolok, Kabupaten Sukabumi, Jawa Barat. Skripsi. Departemen Agronomi dan Hortikultura, Fakultas Pertanian, Institut Pertanian Bogor. Tidak Dipublikasikan.

Peluso, NL. 2003. A Theory of Acces. Feature Rural Socioloy. Vol.02. No.02, 30 Juni 2003. USA: Rural Sociological Society. Hal. 153-181.

TNGHS. 2007. Rencana Pengelolaan Taman Nasional Gunung Halimun Salak Periode 2007-2026. Sukabumi: TNGHS. 